ARTICLE

DOI: $10.1057 /$ s41599-018-0172-y

\title{
The unconditioned in philosophy of religion
}

\author{
Steven Shakespeare (i) ${ }^{1}$
}

\begin{abstract}
This article argues that philosophy of religion should focus on the notion of the unconditioned, rather than God. Such a shift of focus would have a number of advantages. It would loosen the grip of the default theistic framework often used in the field. In turn, this would encourage fresh reflection upon the nature of the unconditioned and its relationship to conditioned entities. In the process, it would facilitate critical conversation about fundamental metaphysical issues across the divide between analytic and continental philosophers. As an initial step, this article offers a working definition of the unconditioned and explores significant developments of the idea through Kant and the early work of Schelling. It argues that light can be cast on the notion of the unconditioned by contemporary analytic debates about essence and grounding, and vice versa. In order to suggest the fruitfulness of this approach, a recent essay in philosophy of religion by Daniel Barber is examined, in which the unconditioned is presented as a differential field immanent to what it conditions; and in which conditioned entities are understood through the notion of modal essence. The article ends with a summary of the advantages of refocusing philosophy of religion on the unconditioned, not least in enabling the discipline to take seriously non-theistic and non-transcendent approaches to ultimate reality.
\end{abstract}

\footnotetext{
${ }^{1}$ Liverpool Hope University, Liverpool L16 9JD, UK. Correspondence and requests for materials should be addressed to S.S. (email: shakess@hope.ac.uk)
} 


\section{Introduction}

will argue that the notion of the unconditioned represents an untapped potential for recasting the scope of philosophy of religion. It raises the possibility of reconsidering or even avoiding the problems encountered by models of transcendent being (notably those which seek to secure God's interaction with the temporal and finite world).

It would be absurd to claim to offer a full articulation and defence of this claim in the space available. My more modest aim here will be to (a) offer a clarification of the concept of the unconditioned via a genealogical consideration of its role in Kant's thought and its aftermath; (b) outline a constructive development of this concept in dialogue with contemporary trends in both analytic and continental metaphysics.

In the course of achieving these aims, I will offer supporting arguments for the possibility of articulating a meaningful version of the unconditioned which will enable progress in resolving metaphysical issues in the philosophy of religion, and ontology more generally. This is necessary, because readers may well suspect the concept of the unconditioned of incurable vagueness. They may not go as far as Carnap (2005), who lists the unconditioned alongside other metaphysical terms, such as God, the absolute and the infinite as 'devoid of meaning', but they may reasonably doubt that it can have precise definition, or that statements involving it can have specifiable truth conditions (after all, how can the unconditioned meaningfully be subject to semantic or epistemological conditions?).

I will therefore begin with some general remarks which briefly contextualise the potential importance of the unconditioned as opposed to dominant paradigms in philosophy of religion (especially the question of what 'religion' actually is). I will then turn to specific objections to the concept of the unconditioned arising from analytic philosophical debates, which will help to orient the investigation.

\section{The unconditioned, religion and theism}

It is obviously true that philosophy of religion need not be defined by, or conducted within, a theistic framework. However, a cursory glance at textbooks, anthologies, handbooks and curricula in Western philosophy reveal that this continues to be the dominant paradigm. ${ }^{1}$

This reflects the influence of philosophical and theological thought in Christianity, and, to a lesser extent, Judaism and Islam in the West. It is through these traditions that Greek philosophy is mediated. There is no denying the richness and diversity to be found in these debates. At the same time, a certain privilege is often given to the notion of a God transcendent to the world, which renders alternative perspectives (one night think of Cusa, Eckhart, Bruno, Spinoza and other 'mystical' traditions) suspect in the eyes of an orthodoxy able to marshal various form so coercion to suppress what is considered heresy.

One might think the loosening of ecclesial authority in the wake of the Enlightenment would help to resolve this narrowing of the field. While there may be truth in that (considering the arguable heterodoxy of thinkers from Kant to Hegel to Schopenhauer), it coincided with the invention of the abstract term 'religion' as a category of human life and study. Rather than being complex traditions defined by their own intrinsic categories, Christianity, Judaism and Islam become variants on an abstract 'theism'. 2

Abstraction in itself might add conceptual analysis. However, it can also close down conceptual possibilities. More nefariously, abstract notions of religion and theism (often equated) have been used to subject heterodox and non-Western traditions and practices to conceptual subsumption: consider the invention of
'Hinduism' as a religion; or the question 'is Buddhism a religion?'; or the missionary assertion of the priority of an original monotheism of which later practices are deviations and corruptions.

None of this means philosophical questions raised in a theistic framework might not be fruitful. But there are reasons, even internal to those traditions considered 'theistic' to loosen the grip on this particular paradigm.

A critical reader might quickly spot a problem. If theism is problematic in its abstraction, why turn to something which sounds even more abstract: the unconditioned? My answer is twofold: for all the apparent hubris of identifying in the unconditioned the fundamental ground of reality, it comes with a necessary dose of critical modesty. As real, but not determined as subject or object, the unconditioned is not defined in advance as theistic or non-theistic. Schelling, as we will see, argues that it is not transcendent, but immanent; a position I endorse and will seek to expand on in the latter parts of this essay. It is obviously open to theists to contest this account. At the same time, the unconditioned invites alternative approaches, whether from neglected emanationist, monistic and pantheistic Western sources, or in terms of such approaches as Advaita (non-dual) and Dvaita (dual) Vedanta; exploration of the unconditional Buddhanature, or of the ultimate identity of nirvana and samsara. These are only a few examples: but even these suggest the potential for developing a critical inferential metaphysical framework able to engage with diverse traditions without presuming a standard ontological model or core in advance.

This connects with the second part of my response to the issue of the abstraction of the unconditioned. As I will explore, I hold that the unconditioned is generic rather than abstract. By this, I mean that the unconditioned is not derived by abstraction from an existing metaphysical commitment; constructively, it is through the non-objectivity and non-subjectivity of the unconditioned that it works as a critical notion within religious and metaphysical traditions. It affirms the possibility of relating to the fundamental structure of reality without prejudging that structure in advance. It therefore allows for rational creativity, the construction of specific metaphysical characterisations of the unconditioned, without deflating it.

Of course, there have been many debates about whether metaphysical concepts should, in part or as a whole, be deflated. This constitutes part of the recent vibrancy of both analytical and continental traditions. In order to take stock of this, I turn to a particularly sharp rejection of metaphysical claims.

\section{From analysis to essence}

Carnap's eliminitativsm. It is worth beginning with Carnap. Although his strict verificationism may not be in vogue, his analysis of propositions remains influential, and his reasons for dismissing metaphysical statements have the advantage of setting the issues in stark relief. Those already familiar with this debate may feel free to skip this short section.

For Carnap, 'the meaning of a word is determined by its criterion of application' (Carnap, 2005, p. 981). What this amounts to is that, for any word to have meaning, it must be possible to state how that word can be verified, what its truth conditions are and from which sentences it is deducible. Carnap proposes to eliminate metaphysical words and statements from meaning because no satisfactory answer can be given to these demands.

In fact, Carnap holds that all three of these stipulations are rephrasings of one question. That at least seems odd, if not question begging: what is the essential connection between 
verification, truth conditions and deducibility, if it has not been assumed in advance that these three are coextensive?

The apparent answer lies in the fact that Carnap's eliminative approach to meaning involves a method of reduction: 'In this way every word of the language is reduced to other words and finally to the words which occur in the so-called 'observation sentences' or 'protocol sentences'. It is through this reduction that the word acquires its meaning' (Carnap, 2005, p. 981).

Carnap immediately adds that the issue of the form and content of these primary sentences has not been settled but can be ignored. What matters, he claims is that such sentences refer to what is 'given'. The radical divergence of views about what this 'given' consists of are rather airily dismissed-for Carnap, we are 'certain' that words have meaning in their reduction to the primary sentences, whatever their characteristics may be.

This is thin gruel in what aspires to be a robust analysis. Protocol sentences fulfil a frankly metaphysical (in the 'bad' sense) role in this schema. They are not specifiable in anything beyond themselves, apart from appeal to an indeterminate givenness. It is thus subject to the critique offered by Sellars (1956) that no cognition can both offer itself as an immediate, independent datum and simultaneously enter into inferential relationships with other cognitions. Inference is always propositionally mediated and thus involves a contextual hermeneuticprecisely what Carnap's postulated 'protocol sentences' refuse.

With this critique, we remain well within seminal traditions of analytic philosophy, whether of Quine's rejection of the dogma of reductionism or Davidson's subsequent refusal of any absolute distinction between empirical datum and conceptual scheme. None of this implies any flight to relativism. As Davidson points out, 'In giving up dependence on the concept of an uninterpreted reality, something outside all schemes and science, we do not relinquish the notion of objective truth - quite the contrary' (Davidson, 1973, p. 20). It is the very rejection of dualism between content and scheme which facilitates investigation of the truth conditions of concepts. Otherwise, we are stuck with an arbitrary and entirely relative relationship between empirical data and expressions of meaning. Carnap's position is self-defeating.

\section{Modal analysis and its limits}

While varieties of inferentialism and holism have grown in response to cruder forms of empiricist epistemology, in itself this does not entail openness to metaphysical questions (or at least, any answers to such questions which go beyond a form of naturalism). It is striking, then, that we have witnessed a revival of metaphysics in analytic philosophy over recent decades, in ways which are relevant to my concerns in this paper.

One reason for this revival was the incapacity of existing logical analysis to deal with counterfactuals and modal statements (i.e., statements of possibility and necessity). How could the truth of statements which asserted that something is possible (but not actual), or actual (but also necessary) be determined? In response to such issues, the language of possible worlds was developed. Possibility and necessity could be understood via a quantified modal logic, where ' $\mathrm{x}$ is possible' translates as something like ' $\mathrm{x}$ obtains in at least one possible world'; and ' $\mathrm{x}$ is necessary' as ' $\mathrm{x}$ obtains in all possible worlds.. ${ }^{3}$

This innovation allowed a proliferation of new analyses and clarifications, but also gave rise to pressing questions: just what is the metaphysical status of possible worlds, for example (see the seminal argument for the reality of possible worlds in Lewis, 1986)? And in more recent years, the adequacy of possible worlds models has been called into question, not least by philosophers such as Kit Fine. Fine $(1994,1995,2005,2009)$ and others argue that quantified modal logic is unable to capture the meaning of essential properties or of consequent asymmetries of dependency (see Lowe 2012 for a good example of this).
Consider, Fine argues, the relationship between Socrates and the set whose sole member is Socrates (the singleton). In whichever possible world the former appears, so does the latter. And yet we would want to say that the singleton depends on Socrates in a way that Socrates does not depend on the singleton. The singleton does not constitute the essence of Socrates, despite them being coterminous over possible worlds.

Through these and other examples, Fine argues that we must define essence in such a way that modal criteria offer a necessary but not sufficient account of it. Modal criteria do not offer an account of the intrinsic nature of the object under consideration, or of relationships of asymmetrical dependency: 'it seems possible to agree on all the modal facts and yet disagree on the essentialist facts' (Fine, 1994, p. 8). Fine offers the example of two philosophers who agree on the necessary differentiation but coexistence of the elements of person, mind and body, who nevertheless disagree on the order of priority between these elements. He comments that this 'shows that even when all questions of necessity have been resolved, questions of their source will remain' (Fine, 1994, p. 8).

Fine's conclusions are of course subject to clarification and debate. However, what we are witnessing in contemporary analytical philosophy is a powerful tendency to contest narrowly analytical accounts of meaning, and a turn to considerations, not only of modal logic and associated metaphysical issues, but also of essence, priority and grounding, for which modal solutions are arguably inadequate.

Grounding and essence. Grounding is of particular importance in this context, because it seeks to specify asymmetrical dependency relationships without reducing all of these to efficient causal connections. In some ways, grounding may evoke a wider notion of causality as exemplified by Aristotle's fourfold classification. However, because the language of causality is often associated with its efficient variant, and because metaphysicians do not want to rule out other non-causal grounding relationships, it seems better to adopt a different terminology.

Grounding concerns an important aspect of the constitutive conditions for states of affairs. Consider the example of the brittleness of a fine bone china plate. It is brittle in virtue of its physical composition and structure. It would be odd to say it its brittleness was caused by its composition in an efficient sense, since brittleness is not an event or state of affairs existing separately from its cause. Nor can we easily analyse this situation in modal terms: to say there is a possible world in which the plate is broken given a minimal trauma is not an explanation of the brittleness of the plate in the actual world. That requires something to be said about the essential nature and consequent dispositions of the plate (nota bene for our concerns later in this paper, that this essential nature could be specified in terms of a differential structure rather than a simple substance).

There is a significant connection with the issue of necessity. Consider the claim of the Euthyphro dialogue that an act is lovable by the gods in virtue of being pious. It would follow from this that it is necessary that if an act is pious, then it is loved by the gods. However, modal analysis can only take us so far in analysing this, since it is also necessary that, if an act is pious, $2+$ $3=5$ (since the latter is true in all possible worlds). However, there is no relevant connection, and so no explanatory link, between the clauses in the second statement. To ask about grounding is to ask about aspects of a situation or object which intrinsically pertain to one another, and therefore to pursue questions of necessity in relation to essence. ${ }^{4}$

Beyond the concerns of thinkers who have been pursuing these questions of essence and ground, does this suggest an opportunity 
to revive or recast questions in philosophy of religion? $?^{5}$ I propose that it does, but that it requires a step away from assumptions about the object of 'religion'-a term which often gets interpreted in blunt ways which assume the prior framework of a Christian, or at least a 'theistic' understanding of absolute reality.

This is where the concept of the unconditioned offers a promising opening. The next section will give a preliminary definition of the concept, and its advantages in connecting with the kind of shift to metaphysical questions of essence and grounds we have traced so far-and how such questions need to be rethought within philosophy of religion.

\section{Defining the unconditioned}

I start with the ex hypothesi statements that:

U1 An entity is unconditioned if and only if its existence and essence is not dependent on or determined by anything else.

And

U2 An entity is unconditioned if and only if it is the source of the constitutive conditions for anything else whatever to exist.

Such statements immediately raise a host of questions, not least whether there is any such thing as the unconditioned in the first place-or whether it can be adequately referred to as 'an entity'! However, I think a coherent working notion of the unconditioned can be at least articulated.

Firstly, we need to distinguish between the unconditioned and what is necessary. Assume that we are interested in necessity de re rather than de dicto (i.e., a necessity pertaining to the object itself rather than to a way of speaking about the object), a modal approach would define this as an object's existence in all possible worlds. However, there is no guarantee that an object's existence in all possible worlds gives it any significant relationship to any or all other objects and states of affairs in those worlds; or that mere occurrence in all possible worlds leaves us any the wiser about what constitutes the necessity of an object. What is it about an object that makes it necessary in this sense? What grounds necessity? What-we might add-constitutes the possibility of possible worlds?

The notion of the unconditioned does not pretend to answer these questions in specific instances, but aims at that which is the essential presupposition of any and every possible condition whatever. Arguably, there might be an unconditioned object that satisfies U1 in every possible world which enters into no other relationship with the rest of the objects and events in that world. However, it would be difficult to specify the sense in which such an object would be 'in' or 'of that world, since it would bear no relation to anything else. If it related to less than the totality of other objects in that world, some account would have to be given of why it related to some and not others. Prima facie, an unconditioned object relating to only some other objects in a possible world would be limited in scope, and thus finite; we would then have to ask what constituted its limits, in which case it would seem difficult to sustain referring to such an object as unconditioned in any meaningful sense.

Such questions deserve further consideration, but for the purposes of this paper, I am reserving the term 'the unconditioned' for that which essentially pertains to the nature of every other possible entity; and upon which every possible entity depends (i.e., every possible entity is possible in virtue of the nature of the unconditioned). The two statements in fact may be translated into each other, but, following Fine's (1995) analogous distinction, I make the assumption clear, and thus establish the putative link between the unconditioned, essence and ground. U2 can thus be further articulated:

$\mathrm{U} 2^{*}$ An entity is unconditioned if and only if it essentially pertains to the nature of every other possible entity and it is that upon which every other entity is asymmetrically dependent; and thus is the source of the constitutive conditions for anything else whatever to exist.

Informally, we might say that the unconditioned, on this view, is the Essence of essence and the Ground of ground; more soberly, that the unconditioned is that in virtue of which every possible world is possible, and every necessary entity is necessary; and is, in the last instance, the ground of any condition or essence whatever which determines an object or state of affairs to be what it is. Every possible conditioned entity is, on this understanding, in a relationship of ultimate asymmetrical dependence on the unconditioned. I will refer to this on occasion as the 'absolute unconditioned', for reasons related to Kant's treatment of it (see below).

Stated in that way, the unconditioned looks a lot like the concept of God, at least God as the first cause, mover or necessary being, familiar from such classical arguments as Aquinas' first three ways. That is no accident, since such arguments do aim to prove that, in my sense, everything depends upon an unconditioned being. However, I avoid reference to God for several reasons. Unlike analytic and other versions of theology, I am not presuming any given divine revelation. I am not committed to the position that the unconditioned has personal characteristics. And I am not assuming that the unconditioned is transcendent, in the sense that it produces possibilities ex nihilo by a free act of will; or that it is unaffected by the possibilities it actualises. This allows for a more critical approach to philosophy of religion.

More positively, the notion of the unconditioned connects with important aspects of Kantian and post-Kantian thought which help to articulate the notion further, and does so in terms of immanent, rather than transcendent causation. By invoking the notion of causation here, I am aware that this might seem to take us away from the concept of grounding, which is usually conceived as a non-causal determination. However, some conceptual slippage may be desirable at this stage; grounding pushes us to think more broadly and adequately about conditioning relationships in toto; in light of this, the way in which ultimate grounds give rise to what is grounded may help us reconceive causal conditions too, such that a broader conception of conditioning connects and encompasses both grounds and causes. Immanent causation-in which the effect is, in an important sense, within the cause-would be an important model here (more on this later; see 'Barber on Unconditioned Expression and Affectivity'). Focusing philosophy of religion on the unconditioned rather than a theistic framework could therefore open up possibilities for rethinking the relationship between contingent objects and necessary grounds/causes in ways which avoid some of the dilemmas facing transcendent models of divine action and relationality. I will offer initial considerations to support this viewthough, of course, they would need further elaboration and are subject to rebuttal from theistic approaches among others.

The next section therefore examines Kant's identification of the importance and role of the idea of the unconditioned, before taking up the critical development of this in the early philosophy of Schelling.

\section{Kant and Schelling on the unconditioned}

Kant. In the Critique of Pure Reason, Kant (1929) argues that reason aims at the unconditioned, in the sense of a totality of all conditions. This makes intuitive sense; if reason is seeking for a complete explanatory account of objects and events in the world, it cannot rest only with a partial account of their conditions. Colloquially, we might say that reason restlessly seeks the big picture: a full explanation of every conditioned reality whatever. Only the unconditioned can provide that. 
However, there is for Kant a vital caveat. Reason may aim at the unconditioned, but this would take us beyond the bounds of possible experience. The understanding, through which the manifold flux of experience is rendered knowable through the categories, can only take us from any conditioned entity to its (relative) condition.

Is reason's teleological orientation toward the unconditioned therefore illusory? It certainly cannot give us cognitive access to the unconditioned, since the unconditioned is not a possible object of experience. However, the idea of the unconditioned still plays a necessary regulative role; it gives the rule to the understanding, in the sense that sets the task and direction of the understanding in conceiving conditioning relationships to the maximal possible extent. This is true, for Kant, not just in logical inferences, but in the real use of reason to guide our investigation of the world. The absolute unconditioned-i.e., that which is unconditioned in all possible relations-is never arrived at, or given in experience; but it is 'indispensably necessary' for the practical use of the understanding (Kant, 1929, p. 319). It is this idea of reason which validates inferential movement-or any grounding relationship-along any series of conditions.

Kant's constraints on the cognitive content of the idea of reason aimed to undermine what he saw as dogmatic metaphysics. The cosmological argument for the existence of God is ruled out as a demonstrative proof, since, for Kant, 'God'-here standing for the unconditioned 'first cause' - cannot be given in experience and known by the understanding. If we claim to prove the existence of God, we really do not know what we are talking about.

Schelling. In many ways, Kant sets the tasks for subsequent philosophy. The critical use of reason against the arbitrariness of 'given' starting points is crucial. It is in the spirit of Kant that Schelling and other 19th century idealists construct their own systems.

That might seem an odd statement, given the metaphysical pretensions we might associate with idealism. However, as Eric Watkins (2014) has shown, Kant's notion of the unconditioned is pivotal for Schelling's formative early work. Schelling takes up the task of making philosophy a scientific discipline, in the sense that its fundamental starting point and principle is not a dogmatic or arbitrary one. The unconditioned plays this role-and Schelling develops it in ways that both further and contest Kantian claims.

When Schelling wrote 'Of the I as the Principle of Philosophy or On the Unconditional in Human Knowledge' in 1795 (Schelling, 1980), he was still much under the influence of Fichte, as the reference to an absolute 'I' suggests. However, the two halves of the title of the essay signify a tension, and possibly a break: to describe the unconditioned in Fichtean terms as an 'I' looks increasingly inadequate as the argument progresses.

Schelling is motivated by the loose ends in Kant's formulation of the issues. In proposing that the unconditioned is a noncognitive idea of reason, Kant fails to determine why the categories of the understanding should take the form they do, or what unifies them. Kant identifies the goal of the understanding as a telos which is forever out of reach, but which nevertheless has a causal influence on the understanding (Kant, 1929 , p. 319). If such an influence is not to be arbitrary or dogmatic, some specification of how the unconditioned enters into conditioning relationships must be offered. In other words the causal, or more broadly, grounding relationship between unconditioned and conditioned needs to be explored. The unconditioned is therefore assumed as a real ground, as a ground of real experience and only as such can its guiding role for the understanding be justified.
A brief excursus into modal language might help to clarify the point. In modal terms, we might plausibly equate Kant's unconditioned with the totality of all possible worlds. However, such an unconditioned totality would tell us nothing about what makes such a totality possible in the first place; or about what (if anything) grounds all possible entities, and thus makes the transition from speculative possibility to conditioned actuality take place. If there are grounds, they are real grounds, grounds in virtue of which something is what it is. The conditioning relationship is not merely logical, but is real and genetic (i.e., it actually gives rise to what would not otherwise exist).

A related point-not directed at Kant specifically, but at variants of noncognitive approaches to metaphysics-is made by Lowe:

By opting for a less ambitious aim, it is hoped that the possibility of a suitably modest metaphysics may be secured. However, such a position is fatally flawed, if its intention is to render 'metaphysical' claims legitimate by construing them as not venturing to speak of how things really are, as opposed to how we must think of them as being. For we, if we are anything, are part of reality ourselves, as are our thoughts, so that to purport to make claims about allegedly necessary features of our thoughts while simultaneously denying that anything is being claimed about the nature of 'reality' is to contradict oneself. (Lowe, 1998, p. 6).

Schelling is therefore looking for a real unconditioned as the principle of philosophy, because it would also be the ground of all reality. However, he is not simply seeking to reinstate metaphysical proofs of the existence of God. The influence of Kant's critical philosophy remains an important one.

The unconditioned is neither subject nor object, insofar as subject and object are mutually determined (the subject is subject as a perceiver/knower of objects, or of itself as objectified; objects are possible objects of a subject's experience or thought). This will ultimately lead Schelling away from his early insistence on referring to the unconditioned as 'I', albeit he takes pains to distinguish this from the empirical subject. Schelling's debt to Fichte is such that, at this stage, he finds in the absolute 'I' a spontaneity in which being and knowing coincide. However, this still presumes that knowing is a fundamental principle, and that the unconditioned should be understood in subjective terms. The later Schelling will acknowledge that the absolute unconditioned cannot be said to be 'conscious' in this way, and that consciousness itself arises out of a more fundamental, preconscious ground (Schelling, 2000).

Even in his early writing, Schelling's exploration of the logic of the unconscious points in this direction: 'My I contains a being which precedes all thinking and imagining' (Schelling, 1980, p. 75). He takes advantage of the etymological fact that the German term for unconditional-unbedingt-suggests that the unconditioned cannot be any kind of thing (Ding). To be a thing is to be conditioned: to have limits or grounds which are not produced or determined by the thing itself. To an extent, this explains why Schelling clings to the notion of an 'absolute I', since the 'I' as subject of thought cannot be related to as a thing without denying its nature (a point reminiscent of those made in philosophy of mind by defenders of qualia such as Nagel and Chalmers). However, since any the subject of our own experience is always finite and grounded, this way of characterising the unconditioned appears arbitrary, on Schelling's own terms.

Key to Schelling's position is that 'the absolute can only be given by the absolute' (Schelling, 1980, p. 75). It can have no precondition, and its 'givenness' cannot be an arbitrary brute fact. Again, we might think this bring him close to a version of theism 
(such as that of Karl Barth) which stresses the transcendence of God, and takes the position that only God can reveal Godself. However, such an act of revelation, received in faith, would itself appear arbitrary to Schelling. In addition, the characterisation of God as conscious agent, transcendently distinct from the world, would entail that God is a conditioned entity. To define God in distinction to anything else is to objectify God.

In contrast, the absolute unconditioned precedes any distinction of subject and object, transcendent and immanent. It is therefore not a concept inasmuch as a concept aids comprehension by gathering a multiplicity or a complexity into a unity (Schelling, 1980, p. 87); although Schelling later refers to it as a 'the generic concept of all reality' which coincides with reality itself (Schelling, 1980, p. 89). Such phrases appear strange, but they are strange under the pressure of thinking the unconditioned at all. As absolute, there cannot be anything outside the unconditioned; it cannot be mediated or conceptually demonstrated without distortion-not because it is at a transcendent distance, but because it is the ultimate ground and identity of what is. In this sense, it is (picking up Spinoza's terminology) the 'immanent' cause or ground of all, rather than an externally determining cause (Schelling, 1980, p. 95).

Recap. These might seem to be heady metaphysical heights (one can almost hear Carnap turning in his grave). A brief recap might bring us back to earth.

Kant plausibly argues that the understanding progresses by moving from the conditioned to the condition. A condition might be a cause, in the efficient sense, but it could also equate to a number of other grounding relationships, as suggested by recent analytic metaphysics. These conditions or grounds fulfil a broadly explanatory role. For instance, they explain why something happens in the way that it does; or manifests its properties in a certain way; or is determined by certain necessities or possibilities according to its essence.

For Kant, the search for conditions cannot ultimately be satisfied by relative explanatory grounds. While these will suffice for practical purposes, they do not exhaust the rational drive itself. Kant argues that reason aims at the unconditioned as the totality of conditions, though it presents it to the understanding only as a regulative idea. Schelling agrees with Kant that reason is restless until it finds the unconditioned; but argues that this must be a real unconditioned, since it is presupposed by any possible entity or experience and it actually gives rise to what it groundsit is not a fictive telos.

As Schelling explores the logic of this idea, it becomes clear that the unconditioned cannot be any kind of distant supernatural entity, but is the immanent ground of all that is. It is not 'a' being. Schelling even denies it can be said to 'exist', since 'existence (Dasein) always signifies a conditioned... being posited, determined by specific conditions' (Schelling, 1980, p. 105). As unconditioned, it cannot be a partial reality, a subject or an object. There is then good reason to suppose that the unconditioned is immanent to what is and to what is possible. The unconditioned, far from being a fantasy object, is in fact the most generic reality of all.

A way thus opens up to talk about some of Carnap's derided terms - the absolute, the unconditioned, being - in ways that do not simply presume a theistic framework, but which can enter into fruitful exchange with both analytic and continental metaphysics.

I will now sketch what may be some of the advantages and problems of this for philosophy of religion before looking at one particular example of how philosophy of religion might be conducted in this alternative guise.

\section{Advantages and problems}

Inferences. A major part of the advantage of this change of focus for philosophy of religion is that it provides a framework for developing adequate logical inferences. Schelling's 'Of the I' is a prime example of a text which analyses the logic of the unconditioned. The moves made are recognisable in the tradition of an Aquinas or a Duns Scotus, but the outcome is very different because Schelling does not presuppose the need to incorporate such notions as God's will or purpose. These elements have been at the core of some key problems in philosophy of religion: the compatibility of evil with divine omnibenevolence and omnipotence; the relation of human free will to divine foreknowledge and sovereignty; the capacity of God to know and interact with the temporal world while maintaining eternity and omniscience (and vice versa). I am not suggesting that such problems magically disappear once by substituting the unconditioned for God (they may emerge in new forms, especially the third one, which Schelling also struggled to resolve); nor, of course, are theistic approaches ruled out, as this would arbitrarily shut down debate. However, philosophers do not have to assume that the only game in town is theism versus atheism.

There are a number of other problems with which a philosophy of religion focused on the unconditioned would have to engage. I will briefly touch on three: the worry about epistemological access and modesty; the general question of whether conditioning/grounding relationships are unitary; and the vexed issue of how the unconditioned relates to and gives rise to the conditioned.

Epistemological modesty. Even setting aside the eliminitavist position on metaphysics, there are questions of the truth conditions of statements about the unconditioned, and a related worry about the lack of epistemological modesty this approach might entail. For instance, Anderson, whose work is at the boundary of analytic and continental approaches, offers a powerful defence for such a modesty as justified by a broadly Kantian perspective, in which a rational yearning for the unconditioned should not be confused with cognitive access to it (Anderson, 2010). ${ }^{6}$

Such questions deserve much fuller consideration than can be offered here. As a very preliminary response, a twofold approach can be articulated. First, a persuasive case is made by Schelling and others that talk of the unconditioned must have ontological, and not merely regulative import. This was touched upon above. The argument is that, if reason is rightly giving the rule to the understanding in directing it to aim at the totality of all conditions, then the validity and success of this in advancing explanatory power implies that we can progress in articulating the fundamental structure of reality as it is, and not merely as it appears to us. The other side to this, however, is that the unconditioned is not simply given in conditioned experience in a straightforward way. As we have seen, for Schelling, it is neither subject nor object, nor can it be mediated conceptually without us revisiting what conceptual articulation might mean. A focus on the unconditioned, then, is not a naïve or bombastic claim to absolute knowledge. It is still restrained by transcendental critique.

The alternative would be to leave us with teleological demands which do not touch on reality, in which case both science and broader issues of human yearning are automatically detached from what there is, and from a rational relationship to what there might be. This kind of perspectivalism neither accounts for nor serves scientific or broader ontological discovery, nor does it offer anything to overcome the unfortunate dualism between desire/ passions and reasons. 
The unity of grounds. Kant distinguishes between different sorts of unconditional: logical, metaphysical and normative. Schelling also discusses the difference between logical conditions and metaphysical ones.

This is echoed in recent discussions of grounding, where the question has been raised: is all grounding basically unitary, with a common nature? Or are there irreducibly different kinds of grounding (Audi, 2012; Koslicki, 2012)? Kant and Schelling ultimately seem to come down on the first position. For all the relative distinctions of conditioning relationships, the unconditioned is absolute; it pertains to all possible conditions. Contemporary discussions may not focus on the possibility of a single unconditioned reality, but still address the basic question of differentiating sorts of grounding relationship.

While I cannot hope to do much more than indicate this as a necessary topic for further research, I repeat my earlier suggestion that a desirable goal for philosophy of religion as focused on the unconditioned would be to clarify a sense of conditioning which encompasses causal and non-causal grounding relationships. The goal would not be a homogenisation of these differences, but a generic account of conditioning which allows for differentiated and specific types. How this might work will be sketched further in the section on Deleuze and Barber (below); an interesting complementary instance would be the neo-Aristotelian metaphysic outlined by Schaffer (2009), in which the whole universe is the unique foundation of grounding relationships and is the sole substance (he dubs this 'priority monism'); derivative entities are implicit within their grounds; and the parts of the universe are derived from it via decomposition. The merits of this framework would obviously need to be examined in detail, but it suggests fruitful lines of interaction between burgeoning ontological approaches in analytical philosophy and philosophy of religion across analytical and continental lines of enquiry.

The unconditioned and the conditioned. Schaffer's proposal highlights a related problem for philosophy of religion: how to conceive the passage from the unconditioned to the conditioned. In theistic terms this connects with the question of how an eternal and immutable God can be understood to cause and interact with a contingent and changing creation, without compromising divine immutability or sovereign freedom. The concern is that there might be no coherent way of understanding this relationship consistently; or that it renders creation a necessary emanation of the divine essence (which may be no problem for some philosophers, but which is at odds with a good deal of the Western monotheistic traditions).

If the presumption is not in favour of theism, the root problem still remains. Schelling's early work characterises the unconditioned in terms that echo accounts of divine nature, insisting that it is immutable and indivisible. He is left with the problem of how such a reality would give rise to something contingent, complex and changing, without placing determinate conditions on the unconditioned (which would be a contradiction) or making the temporal world essentially illusory (which raises problems of its own, given that even illusions have some kind of ontological basis).

Schelling's early solution is that the unconditioned has being only through itself, and so affirms its own being and identity as the ground of everything else. This self-affirmation is shadowed by an exclusion: the unconditioned is not anything other than it is. But this logical statement is then said to have ontological purchase, creating a relationship between what is and is not out of which finite determinations can arise.

Groves (1999) has persuasively pointed out the flaws in this approach. Schelling's break with Fichte comes about because the latter assumes that the Absolute (what we are calling the absolute unconditioned) resembles what it conditions. Specifically, in Fichte's case, the Absolute resembles the empirical subject. However, such a position can only rest on assumption or faith, and appears to undermine the unconditioned nature of the Absolute. We see Schelling struggling with this in his early work, arguing that the unconditioned can resemble nothing objective or subjective, while maintaining a certain privilege for the language of subjectivity and self-knowledge.

For Groves, this leads Schelling to an impasse. If the goal is to explain our conscious experience of the world, the danger is allowing that telos to be retrojected into the ground, so that the ground-and ultimately the unconditioned itself-is understood as a reflection of our consciousness. The transition from unconditioned to conditioned is explained as the self-revelation of God, God's need to become conscious of Godself. But this is to prejudge the nature of the unconditioned as incipient consciousness desiring actualisation. There is an assumption of rational teleological progress in the way the Absolute becomes manifest, such that human reason is itself presumed capable of thinking that manifestation. When this tendency dominates, the Absolute becomes essentially a sheer unity; a transcendent, self-identical, ontotheological ground, incapable of explaining actual differentiation and individuation.

Having surveyed various possible advantages and outstanding problems with the approach I am advocating, we have ended with what I believe is one of the crucial questions it faces. Is there an alternative way of theorising the unconditioned in its relationship to conditions? One which does not arbitrarily figure the unconditioned in the image of the conditioned, but which can overcome the hiatus between what appears to be a qualitative difference between the two? In the next section, we turn to a suggestive recent attempt to do just this, by way of illustrating the potential fruitfulness of doing philosophy of religion differently.

\section{A recent contribution: Barber's Deleuzian account of the unconditioned}

Unconditioned difference. We saw earlier that Schelling makes the case for the unconditioned to be 'immanent' to what it conditions. In other words, the absolute unconditioned is not a transcendent entity, extrinsically related to everything else. To define it in contradistinction to other entities would be to limit and determine it. The conditioned remains, in some sense, in the unconditioned. However, the temptation to then understand the unconditioned according to a model provided by conditioned entities remains strong, and leads to incoherence.

One solution for a metaphysics which rejects transcendent entities is to reject talk of the unconditioned too (perhaps for reasons of epistemology or coherence). However, that is not the approach taken by Schelling, despite the problems he faces articulating his position; he maintains that there is good reason to hold that the unconditioned is the necessary explanatory ground of all that is.

For Groves, the problems which face the characterisation of the unconditioned in more traditionally ontotheological ways drive Schelling in a different path. In his middle period, exemplified by the difficult (incomplete and multi-version) text The Ages of the World, Schelling is abandoning the idea that the unconditioned is sheer immutable unity (Schelling, 2000). Instead, he claims that there is a nonrational aspect of the unconditioned, from which differentiation emerges. The details need not concern us here, though Groves judges that the attempt is still ultimately unsuccessful, because the philosopher's knowledge of this obscure process still presupposes the possibility of a prior, rational and transcendent unity underlying differences. 
So: the unconditioned is called upon to act as an absolute grounding foundation; for the conditioned world to emerge from the unconditioned, it seems that differentiation must be built into, or implicit within the unconditioned to begin with; but to say this suggests that the unconditioned is itself determined in some way, and therefore not absolute. To ground all conditions, the unconditioned must be at odds with itself, and therefore unknowable. As Groves (1999, p. 42) puts it, 'This selfcontradictory result marks the internal limit of foundationalism'.

For Groves, this necessitates, not the abandonment of the unconditioned, but a more consistent articulation of its terms. He turns to Deleuze, as a thinker who takes up the problem of an absolute unconditioned which is 'thought as incommensurable with itself (Groves, 1999, p. 44). This is a strange thought, but one worth following under the pressure of our metaphysical reasoning.

Deleuze undoubtedly affirms the value of a metaphysical orientation towards the unconditioned. As he puts it, in his investigation of the logic of sense, 'the task of a philosophy which does not wish to fall into the traps of consciousness and the cogito is to purge the transcendental field of all resemblance. In order to remain faithful to this exigency, however, we must have something unconditioned...' (Deleuze, 2013, p. 141). This unconditioned determines both the conditions and the conditioned (Deleuze, 2013, p. 140). However, as Deleuze develops this idea, it becomes clear that the 'unconditioned' is nothing like a transcendent entity, but is more like a differential structure, within which all possibilities pre-exist virtually or implicitly. ${ }^{7}$ Deleuze argues that to understand the unconditioned in terms of difference, rather than identity, frees us from the metaphysical prejudice of modelling it after our own subjectivity or reason, and from the incapacity of transcendent entities to ground difference without subsuming it. As Smith puts it "This is the crux of Deleuze's debate with Hegel: Is this unconditioned the "totality" (Hegel) or the “differential” (Deleuze)?' (Smith, 2015, p. 35). Smith locates Deleuze's project as one of 'rethinking the nature of the transcendental field' ${ }^{8}$ As Deleuze is seeking, not just the logical condition of possible experience, but the genetic or generative condition of real experience, his aim is explicitly ontological, even as it questions the adequacy of existing accounts of essence and grounds.

Deleuze's argument is often dense and hard to follow and he tends to be the preserve of continental specialists. This is a pity, as he is engaging with issues of sense, modality, essence and metaphysics in general which engage the interests of analytic philosophers (Deleuze himself was a great admirer of Hume and Russell). In order to bridge this gap, rather than trying the impossible task of summarising Deleuze's thought in the space available, I will examine the use made of his notion of the unconditioned as part of a recent contribution to philosophy of religion by Daniel Barber.

Barber on unconditioned expression and affectivity. Barber's work ranges much more widely than my focus here, across questions of the Christian origins of modern secularism, and the ethical and political refusal of consequent ways of organising and construing worlds. My concern is the part played in his analysis by the unconditioned, as interpreted via Deleuze.

One of the challenges Barber (2014) sets himself is to give an account of genuine change and novelty within a metaphysical framework of pure immanence. Taking his cue from Deleuze and others, this immanence is not relative to, or defined over against a transcendence. There is no metaphysically transcendent dimension from which 'what there is' derives its origin, nature or purpose. The problem is: such a metaphysical immanence seems to leave no room for any possibility of changing or resisting the conditions in which we find ourselves. If 'what there is' is what there is, there can be nothing else: nowhere to go. No exit.

That may not be a problem for a determinist. But, leaving aside problems determinism might face in general, it is worth asking if this is a necessary consequence of a commitment to unconditioned immanence as the metaphysical framework. Our substantive philosophical question remains: how does such an unconditioned function to ground a world which is temporal, which does change? How to avoid characterising it, as Schelling does at times, as an immutable clone of transcendence?

Barber adopts the model of expression in order to tackle this. The unconditioned, if it is to be the ground of all conditions (as per our definition $U 2^{\star}$ ), cannot be inert. And: if there is no transcendent dimension or 'reservoir' of being (no deus ex machina), then the unconditioned must itself be the substance of which all else is a modification. This is a Spinozist point, taken up by Deleuze in a new guise. There can only be one absolute substance, which is through itself-anything else is conditioned by its specific determinations and limits. The Deleuzian twist is that this substance is not something standing over and above (or under) its modes; it is immanent to them: 'an unconditioned power that is simultaneously substantive and modificatory - a power of substantial modification' (Barber, 2014, p. 45).

Barber then talks of the unconditioned expressing itself in determined forms or modes. As finite and contingent effects, these modes are distinct from the unconditioned and one another. However, since the unconditioned is an immanent cause, the effects remain within it: they do not constitute new substances, in the strong sense. What they are is modal essences. They have and persist in their own nature and being, but this is not something immutably fixed. Modal essences may not just be traditional discrete objects, but situations and configurations (indeed discrete objects themselves have and enter into complex relationships between whole and parts). Just as we, in ordinary life, have little problem identifying a chair, so we can also identify a song, a party, a political movement, an ant colony or a corporation. Of course, the definition of such modal essences may still be contested, and it will be increasingly difficult to separate analysis from normative judgement (this in itself suggests further work is needed on the interrelation between normativity, epistemology and ontology). But the point remains: modal essences can still be identified, while preserving the contingency and complexity of the relations from which they are formed. They are characterised by a structural persistence in being necessary for certain effects and affects to take place; but they are not selfgrounding: 'modes are the expressions of the power to which they give determinacy' (Barber, 2014, p. 47). Using the term 'God' in its Spinozist sense, as also sometimes adopted by Deleuze, Barber writes:

Modes are distinguished from God insofar as they are effects, insofar as they are not causes of themselves-yet this does not place them outside or beneath the causal power. A modal essence is a degree of power, but this power is not other than the power of God, for modal power and divine power are in immanence (Barber, 2014, p. 46).

For Barber, then, the unconditioned is expressed. However, since its modes of expression are not separate from it, it is in turn affected by then. This affectivity then catalyses new expressions, and the process continues. There is feedback between the unconditioned and its contingent expressions: 'The immanence of cause and effect introduces affection into the heart of immanence' (Barber, 2014, p. 46).

How can this be, without compromising the unconditioned? Remember that we are not talking about the unconditioned as a 
transcendent object or subject. Assertions about the immutability of the unconditioned determine it as fixed, and cannot account for its giving rise to and relating to conditions. Rather than immutability, a better characterisation would be inexhaustibility. The unconditioned is something like the virtual differential structure within which actual determinations arise. As unconditioned, it cannot be exhausted by any limit or any other reality. However, in the interaction between the unconditioned as ground and its finite determinations, certain virtual differences are suspended, others are brought to the fore. By 'virtual' is meant something more than simply 'possible'; but that which is the generative power of possibilities (and this is why we can still talk of the unconditioned as ultimate essence and ground, even as we need to recast those terms in light of its differential structure and capacity for receiving affects). Affectivity can thus be introduced, while preserving asymmetry.

Modal essences and instauration. Key to the consistency of this line of thinking is the nature of a modal essence. Is such a thing a contradiction in terms? Where every mode is an expression of the unconditioned, in what sense can it have and retain its own being?

Deleuze identifies modal essences as a key feature of Spinoza's philosophy. This is a tricky area in the interpretation of Spinoza, because he is himself far from clear on how modal essences are individuated. At times, he appears to suggest that such essences are indistinguishable from the quality of the absolute (the unconditioned, in our parlance) they express. If this is the case, it becomes hard to see how such essences are anything more than fictions or arbitrary distinctions whose reality is ultimately to be dissolved into the absolute. If an essence is in some sense constitutive of the real nature of an entity, modal essences do not seem to fit the bill.

It could be argued that modal essences are distinguished by their instantiation in actually existing entities, but this is surely putting the existential cart before the ontological horse. If modal essences are indistinguishable, then there is no meaningful sense in which actual entities instantiate them. Better to grasp the nettle and go for Sartre's 'existence before essence' approach, and have done with essentialism altogether.

Deleuze tries to navigate a way through this (Deleuze, 1992, p. 191-199). Drawing on Duns Scotus, he argues that modal essences are not distinguished only extensively, in their actual existence, but also intensively: as degrees of the qualitative power they express. Using Scotus' example of a white wall, we can discern degrees of whiteness, which vary in their intensity, without altering the quality of whiteness as such. Such intensities have a singular degree, even if they are not instantiated in anything actually existing. This singular degree of a quality is a modal essence.

A problem remains, however. As Philip Goodchild argues, Deleuze's position implies that philosophy cannot think these virtual, intensive degrees of power except in the abstract. They remain indeterminable for thought. While this might appear to be a welcome limitation of the hubris of philosophy, it reintroduces an impersonal, undifferentiated 'pure being' as a substrate. In this sense, 'his work sounds like a theology of the indeterminable'influenced by Scotus' notion of a univocal, neuter being (Goodchild, 2001, p. 163). Modal essences thus fail in their role as determinations of a singular reality. They are epiphenomenal.

Goodchild's response is a reconfiguration of how the unconditioned may be thought. Rather than as neutral, impersonal and indistinct, it can be thought of in its 'eminence and perfection' (Goodchild, 2001, p. 163). There is no pure, neutral being, but an infinite unconditioned power, which is implicated in its finite modes of expression. Crucially, this includes the mode of expression - thought, wisdom - whereby we try to think the infinite. There is not being or the unconditioned on the one hand and thinking on the other; but thinking itself is a mode of the infinite. Thus, how thinking is practised, its ethics and its politics, become critical issues for the philosophy of religion.

The extent to which Goodchild's critique of Deleuze is accepted may be debated by specialists. In any case, Barber's own Deleuzeinflected ontology is very much in tune with Goodchild's on this point. Barber is ultimately concerned with the creation of new possibilities out of the giveness of any state of affairs or any world. As the unconditioned is expressed, so the expression affects the unconditioned, calling out new avenues for thinking and acting. The unconditioned is expressed in determinate ways, through an indelible historical track; and yet the unconditioned power of reexpression remains within each situation.

Without therefore slipping into the badly formed dogmatism of a subject-object schema, the groundwork is laid for a productive thinking of essence in relation to the unconditioned: and, precisely because such a thinking is productive, it cannot remain divorced from intrinsic questions of agency, ethics and responsibility. This may be a significant way in which analytic metaphysics needs to be affected in turn by its continental sibling, so that it does not present ontological thinking as noncontextually devoid of any ethical and political positioning. The point is not to advance some form of historicist relativism ('every thought is historical and relative to its context, therefore there is no truth of the matter') but to insist on the determinate being of thinking itself, and the actuality of philosophy of religion as a mode of the unconditioned which both expresses and shapes what is possible. Philosophy of religion is therefore not merely representational, but is productively involved in testing the limits of worlds.

Here, multiple lines of connection might be explored. One is the work done on individuation by thinkers such as Gilbert Simondon and Etienne Souriau. The latter in particular seeks to think the plurality of modes of being and how they come into existence. He utilises the term 'instauration' for this, as exemplified by the process of the work of art (Souriau, 2015). The artist works with a material, a material whose real nature, its persistence and resistance in being, is integral to the work. The artist is neither imposing form on a blank reality, nor simply discovering an object already formed and hidden within the material. There is instead a 'drawing out', in which artist and matter share in the characteristics of subject and object, in which both are affecting and affected. Such a notion of creativity helpfully draws us back to both talk of essences and the productive power of the unconditioned. Again, links to existing debates in analytic and process metaphysics and aesthetics could be fruitfully explored.

Far more would need to be said to contextualise the work of Barber and these related modes of thought, let alone to sift them critically. ${ }^{9}$ However, I hope enough has been detailed here to suggest a fruitful line of enquiry, in which the unconditioned is a candidate for a significant role in metaphysics and philosophy of religion, and in which it helps to recast fundamental issues in these fields. I have throughout advocated an immanent account of the unconditioned, but of course more argument would be required to justify such a stance adequately. This does not at all preclude theistic approaches to philosophy of religion, or those which emphasise the transcendence of the unconditioned, but it offers a critical research program in which such theories and models can be tested. I will finish by summarising what I think are the key aspects of this area of potential research. 


\section{Conclusion}

I have made the case that refocusing philosophy of religion on the unconditioned has a number of advantages:

- It frees us from a presumption that a theistic framework is the default one for the field. As such, it allows for the kind of attention to immanent accounts of the unconditioned which I have favoured here, and opens up new ways of tackling vexed questions about the unconditioned in relation to the conditioned. Although I have not had space to open this up further, it also offers a potential mode of doing philosophy of religion with an openness to non-monotheistic traditions, without organising or subordinating the latter to a notion of the absolute conceived as immutable and timeless.

- It connects to debates about the fundamental structures of reality, about essence and grounds. It opens space for critically examining immanent accounts of conditioning relationships, and modal/differential/dynamic accounts of essence. It therefore allows for a more fruitful engagement between analytic and continental philosophers, in which the mode of thinking that is philosophy of religion becomes productive material, raising issues of philosophical agency and the responsibility of thought.

- Again, though space has not allowed this to be developed, a focus on the unconditioned can also recast questions of agency, of how modal essences can be received and reexpressed. It raises the question of how the unconditioned might be expressed within religious traditions (think of Tillich's recasting of God as the object of ultimate concern; or Kierkegaard's analysis of 'unconditional' joy and obedience in his edifying discourses).

Huge questions remain; analytic philosophers may feel I have played fast and loose with certain terms and moves, though I freely admit that detailed work would need to be done on the structure of arguments which here can only be sketched. Continental thinkers may worry that I am trying to make their work 'respectable' in the eyes of analytical traditions, reintroducing notions of essence about which there is justified suspicion. However, I hope the section on Deleuze and Barber gives the lie to this; continental traditions are evidently engaging with metaphysics on their own terms. My point is that it does no one any good for philosophical idiolects to separate themselves off from one another, not least when there is such interesting exploratory work being done in metaphysics across the board. The notion of the unconditioned is no panacea, but can be a catalyst for unlocking metaphysical creativity in philosophy of religion.

Received: 6 July 2018 Accepted: 12 September 2018

Published online: 02 October 2018

\section{Notes}

1 The most significant attempt to develop a pluralist methodology for philosophy of religion has arguably been that of John Hick, but his later work (Hick 2005) still offers a Kantian approach that, for reasons given in the body of this paper, I believe are metaphysically inadequate.

2 A genealogical account of this is offered by Buckley (2009).

3 A good way into these debates is Borghini (2016). Significant contributions to thinking about modality have been made by Alvin Plantinga, also known for his work in philosophy of religion, see Plantinga $(1974,2003)$.

4 For orientation in this area, see Bliss and Trogdon (2016) and Correia and Schnieder (2012). A foreshadowing of these concerns in philosophy of religion is arguably found in Norman Malcolm's famous article on the ontological argument, with its distinction between the predicate status of mere existence and necessary existence. See Malcolm (1960).
5 Recent years have already seen the growth of a significant tendency: analytic theology. This takes analytic methods to examine the meaning and coherence of a divine revelation received in faith. However, the appeal to revelation itself raises questions about the status of any 'given', and underscores longstanding problems about the relationship between God as a transcendent entity and the temporal, finite world. See Crisp and Rea (2009).

6 For a fuller defence of Kant's approach to philosophy of religion, see Firestone and Jacobs (2008)

7 It would be worth contrasting this with Sider (2011), who prioritises fundamentality in terms of structure in his metaphysics (as opposed to essence or necessity).

8 For further development of this theme, see the various essays in Smith (2012).

9 For a critique of Deleuzian immanence relevant to philosophy of religion (see Haynes, 2012); for further relevant reflections, see the essays in Bryden (2001).

\section{References}

Anderson PS (2010) Pure reason and contemporary philosophy of religion: the rational striving in and for truth. Int J Philos Relig 68:95-106

Audi P (2012) A clarification and defense and the notion of grounding. In: Correia F and Schnieder B (eds), pp. 101-121

Barber D (2014) Deleuze and the naming of god: post-secularism and the future of immanence. Edinburgh University Press, Edinburgh

Bliss R and Trogdon K (2016) Metaphysical grounding. In: Zalta EN (ed) The Stanford encyclopedia of philosophy 2016. Available from https://plato. stanford.edu/entries/grounding/

Borghini A (2016) A critical introduction to the metaphysics of modality. Bloomsbury, London and New York, NY

Buckley M (2009) At the origins of modern atheism. Yale University Press, New Haven

Bryden M (ed.) (2001) Deleuze and religion. Routledge, London and New York, NY

Carnap R (2005) The elimination of metaphysics through logical analysis of language. In: Adams H, Searle L (eds) Critical theory since Plato 2005. Thomson, Boston, p 980-989

Chalmers D, Manley D, Wasserman R (eds) (2009) Metametaphysics: new essays on the foundations of ontology. Oxford University Press, Oxford

Crisp O, Rea M (eds) (2009) Analytic theology: new essays in the philosophy of theology. Oxford University Press, Oxford

Davidson D (1973) On the very idea of a conceptual scheme. Proc Address Am Philos Assoc 47:5-20

Deleuze G (1992) Expressionism in philosophy: Spinoza. Zone Books, New York, NY

Deleuze G (2013) The logic of sense. Bloomsbury, London and New York, NY

Correia F, Schnieder B (eds) (2012) Metaphysical grounding: understanding the structure of reality. Cambridge University Press, Cambridge

Fine K (1994) Essence and modality. Philos Perspect 8:1-16

Fine K (1995) The logic of essence. J Philos Log 24(3):241-273

Fine K (2005) Modality and tense: philosophical papers. Clarendon, Oxford

Fine K (2009) The question of ontology. In: Chalmers D, Manley D and Wasserman R (eds), pp. 157-177

Firestone C, Jacobs N (2008) In defense of Kant's religion. Indiana University Press, Indianapolis

Goodchild P (2001) Why is philosophy so compromised with God?. In: Bryden M (ed.), pp. 156-166

Groves C (1999) Ecstasy of reason, crisis of reason: schelling and absolute difference. Pli 8:25-45

Haynes P (2012) Immanent transcendence: reconfiguring materialism in continental philosophy. Bloomsbury, London and New York, NY

Hick J (2005) An interpretation of religion: human responses to the transcendent. Yale University Press, New Haven

Kant I (1929) Critique of pure reason. Macmillan, Basingstoke and London

Koslicki K (2012) Varieties of ontological dependence. In: Correia F and Schnieder B (eds), pp. 186-213

Lewis D (1986) On the plurality of worlds. Clarendon Press, Oxford

Lowe EJ (1998) The possibility of metaphysics: substance, identity and time. Clarendon, Oxford

Lowe EJ (2012) What is the source of our knowledge of modal truths? Mind 121 (484):919-950

Malcolm N (1960) Anselm's ontological arguments Philos Rev 69(1):41-62

Plantinga A (1974) The nature of necessity. Clarendon, Oxford

Plantinga A (2003) Essays in the metaphysics of modality. Oxford University press, Oxford

Schaffer J (2009) On what grounds what. In: Chalmers D, Manley D and Wasserman R (eds), pp. 347-383

Schelling FWJ (1980) The unconditional in human knowledge: four early essays 1794-1796. Bucknell University Press, Lewisburg

Schelling FWJ (2000) The ages of the world. SUNY, New York, NY

Sellars W (1956) Empiricism and the philosophy of mind. In: Feigl H, Scriven M (eds) Minnesota studies in the philosophy of science, volume I: the 
foundations of science and the concepts of psychology and psychoanalysis. University of Minnesota Press, Chicago, p 253-329

Sider T (2011) Writing the book of the world. Oxford University Press, Oxford Smith D (2012) Essays on Deleuze. Edinburgh University Press, Edinburgh

Smith D (2015) Deleuze, Kant and the transcendental field. In: Lundy C, Vodd D

(eds) At The edges of thought: Deleuze and post-Kantian philosophy. Edinburgh University Press, Edinburgh, p 25-43

Souriau E (2015) The different modes of existence. Univocal, Minneapolis

Watkins E (2014) The early Schelling on the unconditioned. In: Ostaric L (ed.)

Interpreting Schelling: critical essays 2014. Cambridge University Press, Cambridge, p 10-31

\section{Data availability}

Data sharing not applicable to this article as no datasets were generated or analysed during the current study.

\section{Additional information}

Competing interests: The author declares no competing interests.

Reprints and permission information is available online at http://www.nature.com/ reprints
Publisher's note: Springer Nature remains neutral with regard to jurisdictional claims in published maps and institutional affiliations.

(c) (i) Open Access This article is licensed under a Creative Commons Attribution 4.0 International License, which permits use, sharing, adaptation, distribution and reproduction in any medium or format, as long as you give appropriate credit to the original author(s) and the source, provide a link to the Creative Commons license, and indicate if changes were made. The images or other third party material in this article are included in the article's Creative Commons license, unless indicated otherwise in a credit line to the material. If material is not included in the article's Creative Commons license and your intended use is not permitted by statutory regulation or exceeds the permitted use, you will need to obtain permission directly from the copyright holder. To view a copy of this license, visit http://creativecommons.org/ licenses/by/4.0/.

(C) The Author(s) 2018 